\title{
Initial benzodiazepine use and improved health-related quality of life
}

\author{
- Rolf van Hulten, Bart Teeuw, Albert Bakker and Hubert G. Leufkens
}

Pharm World Sci (2005) 27: 41-46

๑) Springer 2005

R. van Hulten (correspondence, e-mail:

r.p.vanhulten@pharm.uu.nl), K.B. Teeuw, A. Bakker, H.G. Leufkens: Department of Pharmacoepidemiology and

Pharmacotherapy, Utrecht University, P.O. Box 80.082, 3508

TB Utrecht, The Netherlands

Key words

Benzodiazepines

Health status

Quality of life

Rand-36

Summary measures

The Netherlands

\section{Abstract}

Objective: The health-related quality of life (HRQOL) of initial benzodiazepine users was measured over time. Furthermore, benzodiazepineusage characteristics as determinants of change in mental and physical health status of the benzodiazepine users were examined.

Methods: In the only pharmacy of a Dutch community of

13500 and during four months from November 1994, all patients with a benzodiazepine prescription and no history of benzodiazepine use over a period of 12 months before inclusion, were invited to participate. A total of 106 initial benzodiazepine users were matched for age and gender. In a six-month follow-up study, HRQOL was measured with the RAND-36. Consequently, in a nested case control design, determinants of change in mental and physical functioning over the six-month period were analysed using the Mental Component Summary and the Physical Component Summary. Results: At baseline, initial benzodiazepine users showed a lower HRQOL as compared to reference subjects. After six-month follow-up, benzodiazepine users presented an absolute increase in $\mathrm{HROOL}$, while the reference subjects maintained a stable HRQOL. Diazepam and the male gender were associated with an increase in physical functioning over time. Younger age, a lower daily dose $(\mathrm{DDD}<0.75)$ and a period of use between 16 and 60 days were associated with better mental functioning over time.

Conclusion: This study is one of the first to associate improvement in HROOL over time of starting benzodiazepine users with specific usage characteristics, such as limited duration of use and a low dosage.

Accepted March 2004

\section{Introduction}

When introduced, benzodiazepines were generally regarded as a clear improvement on older drugs such as barbiturates ${ }^{1}$. However, several early reports stressed the potential risk of dependence as a result of prolonged use ${ }^{2-5}$. Despite this risk, benzodiazepines have become some of the most widely prescribed drugs in industrialised countries ${ }^{6-8}$. Although some evidence has been found for their greater effectiveness in the treatment of anxiety than for insomnia ${ }^{9,10}$, clinical trials have demonstrated their effectiveness and the relative absence of serious side effects ${ }^{11}, 12$. In contrast, several authors have raised doubts about their effectiveness over time ${ }^{9,13-15}$. Large follow-up studies and clinical trials of sufficient duration (most are of four weeks or less) are lacking, which resulted in a scarcity of information on the effects of long-term use as opposed to short-term use ${ }^{12,16}$.

Most studies that addressed the impact of benzodiazepine use on the health status of their users have shown both an impaired mental as well as physical functioning ${ }^{17-24}$. These studies mostly compared long-term benzodiazepine users to reference subjects from the general population. The evidence for impaired functioning raised the question whether morbidity and/or benzodiazepine therapy contribute to this impaired health. Recently, Douglas Ried et al., using a Kaiser Permanente database, found that benzodiazepine exposure slightly predicted functional status in older people. This association was independent of sociodemographic factors and several medical conditions, mainly physical ones ${ }^{25}$.

Benzodiazepine use might be an appropriate therapy for their respective indications ${ }^{26}$. Although benzodiazepines provide symptomatic relief, they can, if prescribed carefully, improve the quality of life of the patient ${ }^{26}$. In this observational follow-up study, the effect of benzodiazepine use on the health status of initial users was compared to reference subjects from the general population during a follow-up period of six months. Furthermore, the study identified the determinants of change in health-related quality of life in the group of initial benzodiazepine users.

\section{Method}

\section{Study population}

Data were obtained from individuals living in a geographically concise area of approximately 13500 inhabitants in the north-west of the Netherlands, with 12500 living in the central community and 1000 in the rural surroundings. During a period of four months from November 1994, all initial benzodiazepine users living in this area and presenting a benzodiazepine prescription in the only local pharmacy, were invited by telephone to participate in this study. The automated pharmacy database contained the complete medication histories of the catchment population. No history of prior benzodiazepine use was generated from the pharmacy data and defined as no benzodiazepine use in a period of 12 months before inclusion. In order to control for influences of time and season, initial benzodiazepine users were matched with reference individuals from the general population (nonbenzodiazepine-using population controls who were identified from the pharmacy database) with respect to gender and age ( \pm one year). Informed consent to analyse their medication histories and questionnaires was obtained in the pharmacy.

\section{Questionnaire and quality of life assessment}

The self-administered questionnaire addressed the following aspects: individual characteristics such as marital status and education. Furthermore, it incorporated the RAND 36-item Health Survey (RAND-36). The RAND-36 is a generic instrument, measuring the whole spectrum of function, disability, and distress. It It consists of eight subscales: physical function, social function, role limitations due to physical problems, role limitations due to emotional problems, mental health, vitality, pain, and general health percep- 
tion $^{27-29}$. The Dutch version of the RAND-36 has previously been tested and validated ${ }^{27}$.

To address the mental and physical components of this generic scale, the eight RAND-36 subscales were aggregated in two summary measures of physical and mental health, the physical (PCS) and mental (MCS) component summary. In earlier reports, the PCS and MCS have been demonstrated to be a reliable screening tool for physical and mental diseases ${ }^{30,31}$. The PCS and MCS scales are marked using a norm-based $(50,10)$ method. Both have a mean of 50 and a standard deviation of 10 in the general US population. US norm data are applied because at the time of study no Dutch data were available. In the present study, change in HRQOL over time was dichotomised at a cut-off point of a ten-point increase in PCS or MCS to represent a change over time.

\section{Pharmacy data}

Benzodiazepine usage was classified on the basis of the benzodiazepine that had been prescribed initially (diazepam, oxazepam, temazepam or other), the period of use ( $<16$ days, 16 to 60 days, $>60$ days), dosage on the basis of defined daily dose (DDD) $(<0.75$, $0.75-1.25,>1.25$ ), episodes of use (one or more periods of benzodiazepine use separated by a period of no benzodiazepine use for more than 30 days), and switching to another benzodiazepine. DDD equivalents were calculated by dividing the prescribed daily dose by the DDD of the benzodiazepine.

As indicator of chronic disease status, the chronic disease score (CDS) was calculated according to Von Korff ${ }^{33}$. The CDS score is a combined score, taking into account various drug classes as a proxy for long-term diseases. The CDS was measured on basis of the complete pharmacy data of the one-year interval preceding inclusion. Furthermore, concurrent antidepressant and analgesic use was analysed to control for possible co morbidity or polypharmacy.

\section{Statistical analysis}

Data were analysed with the statistical programs SPSS for Windows, Release 6.1 (SPSS Inc., Chicago, Illinois). Change in HRQOL over time between initial benzodiazepine users and reference subjects was analysed with the paired Wilcoxon test. Determinants of change in HRQOL over a six-month follow-up were analysed with logistic regression modelling in a nested casecontrol study. Cases and controls were found after dichotomization. Cases were defined as showing an improvement in either PCS or MCS of 10 points or more.

\section{Results}

\section{Response}

A group of 159 initial benzodiazepine users who presented a benzodiazepine prescription during the inclusion period were asked to participate. Of these, 41 persons refused to participate (mean age 50 years [SD $13.87], 37 \%$ male). The resulting response rate was $74 \%$. Furthermore, the follow-up data from a group of 12 subjects were incomplete. Therefore, a total of 106 initial benzodiazepine users and 106 matched reference subjects were evaluated.

\section{Individual characteristics}

Population characteristics of both study groups are shown in Table 1. Most initial benzodiazepine users were women (61.3\%). The mean age of the participants was 47 years (SD 14; median: 48 years) and was the same for men and women. In both the benzodiazepine $(77.4 \%)$ and the reference $(87.7 \%)$ group, the majority of the respondents were either married or living with a partner. No significant differences for the following individual characteristics were observed: higher additional education; employment status; selfreported alcohol; antidepressant; and analgesic use. Consumption of medical services (self-reported visits to either general practitioner or mental-healthcare specialist) was higher in the group of initial benzodiazepine users. Furthermore, chronic disease, reflected by the CDS score, was more prominent in the benzodiazepine user group as well.

\section{Health status characteristics}

Baseline results of HRQOL (Table 2) showed statistically significant lower functioning in initial benzodiazepine users for all dimensions of the RAND-36 as compared to reference subjects. After a six-month follow-up, a significant absolute increase in functioning was observed in this group, while reference subjects maintained a stable health status (Table 2 and Figure 1). The largest differences (absolute change) over time were observed for role functioning (both for physical and emotional problems). For the latter subscales, initial scores were low in the benzodiazepine users (50.9\% for role limitation physical and $59.4 \%$ for role limitation emotional). Change in general health perception (3.1\%) in the benzodiazepine group was small, as were the baseline differences between the two groups (11.5\%).

\section{Benzodiazepine usage characteristics}

Table 3 indicates the usage characteristics at the start of benzodiazepine use and during a six-month followup. Three drugs - diazepam, oxazepam and temazepam - accounted for nearly 80 per cent of all initial prescriptions. Most initial prescriptions were of a relatively low dosage (DDD equivalent $<0.75$ ) or had a DDD equivalent of around 1 ; only $9.4 \%$ had a DDD equivalent higher than 1.25. A small group of $10 \%$ of the first-time users continued use for more than 60 days. Only five users switched to another benzodiazepine during the follow-up period.

\section{Determinants of change in mental and physical functioning}

Composite summaries of change in mental (MCS) and physical (PCS) functioning were calculated and analysed over time for the initial benzodiazepine users. Because of missing values on the subscale level, summary scales could be calculated for $92(87 \%)$ of the subjects. Cases were defined as individuals showing a change in PCS or MCS of 10 points or more. Of the subjects, 29 (32\%) had a change in PCS of 10 points or more; 43 (47\%) subjects had a change in MCS of 10 points or more. Binary logistic regression modelling was applied in a nested case-control study design (Table 4). The analyses considered the relation to characteristics of benzodiazepine usage including six variables. Because of the low number of switches (five), this parameter was not included in the analysis. 
An increased odds ratio of the variable indicates an increased risk for better functioning over time. For both outcome parameters (PCS and MCS), benzodiazepine usage was associated with a better perceived health status over time. The initial benzodiazepine was a factor in the change in physical functioning (PCS). Diazepam use was associated with an increase in physical functioning. Change in mental functioning (MCS) over time was associated with the initial benzodiazepine as well. For mental functioning, use of benzodiazepines other than oxazepam, temazepam, and diazepam was associated with better mental functioning. Furthermore, a low dosage (DDD $<0.75)$ and a limited period of use (period of use between 16 and 60 days) were also associated with better mental functioning over time. A trend was observed for an association with unstable use.

\section{Discussion}

In this study, benzodiazepine use was associated with an increase in HRQOL over time. At baseline, a large discrepancy in HRQOL was observed between initial benzodiazepine users and matched general population controls. After 6 months, initial benzodiazepine users showed a considerable increase in health status (up to $25 \%$ absolute increase), while the controls remained stable. This study is one of the first to associate benzodiazepine use with an increase in HRQOL in a population-based study of initial benzodiazepine users over a longer time period.

Two limitations of the study should be clearly pointed out. First of all, a limitation concerning the study design; although the increase in HRQOL over 6 months was considerable (up to $25 \%$ absolute increase), this study can only suggest that the use of

Table 1 Baseline population characteristics

\begin{tabular}{|c|c|c|c|c|c|}
\hline & & \multicolumn{2}{|c|}{ Benzodiazepine users } & \multicolumn{2}{|c|}{ Reference subjects } \\
\hline & & $n$ & $\%$ & $n$ & $\%$ \\
\hline \multirow[t]{2}{*}{ Marital status } & Couple & 82 & 77.4 & 93 & 87.7 \\
\hline & Single & 24 & 22.6 & 12 & 11.3 \\
\hline \multirow[t]{2}{*}{ Education } & Primary school & 10 & 9.4 & 13 & 12.3 \\
\hline & Additional & 96 & 90.6 & 93 & 87.7 \\
\hline \multirow[t]{2}{*}{ Employment status } & Working & 43 & 40.6 & 43 & 40.6 \\
\hline & Other & 63 & 59.4 & 63 & 59.4 \\
\hline \multirow[t]{3}{*}{ Alcohol use } & Low & 32 & 30.2 & 23 & 21.7 \\
\hline & Moderate & 49 & 46.2 & 54 & 50.9 \\
\hline & High & 25 & 23.6 & 29 & 27.4 \\
\hline \multirow[t]{5}{*}{ Number of contacts with GP * } & None & 3 & 2.8 & 25 & 23.6 \\
\hline & 1 & 12 & 11.3 & 25 & 23.6 \\
\hline & 2 & 28 & 26.4 & 14 & 13.2 \\
\hline & 3 & 18 & 17.0 & 18 & 17.0 \\
\hline & $>3$ & 43 & 40.6 & 24 & 22.6 \\
\hline \multirow{5}{*}{$\begin{array}{l}\text { Contact with mental-health specialist } \\
\text { (psychiatrist, psychologist, etc.) } \\
\text { CDS score }\end{array}$} & No & 83 & 78.3 & 102 & $96.2^{*}$ \\
\hline & Yes & 21 & 19.8 & 4 & 3.8 \\
\hline & 0 & 58 & 54.7 & 80 & $75.5^{*}$ \\
\hline & $1-2$ & 27 & 25.5 & 13 & 12.3 \\
\hline & $>2$ & 21 & 19.8 & 13 & 12.3 \\
\hline \multicolumn{2}{|l|}{ Antidepressant use } & 7 & 6.6 & 3 & 2.8 \\
\hline \multicolumn{2}{|l|}{ Analgesic use } & 16 & 15.1 & 14 & 13.2 \\
\hline
\end{tabular}

*Mantel-Haenszel chi-square test; $P<0.05$.

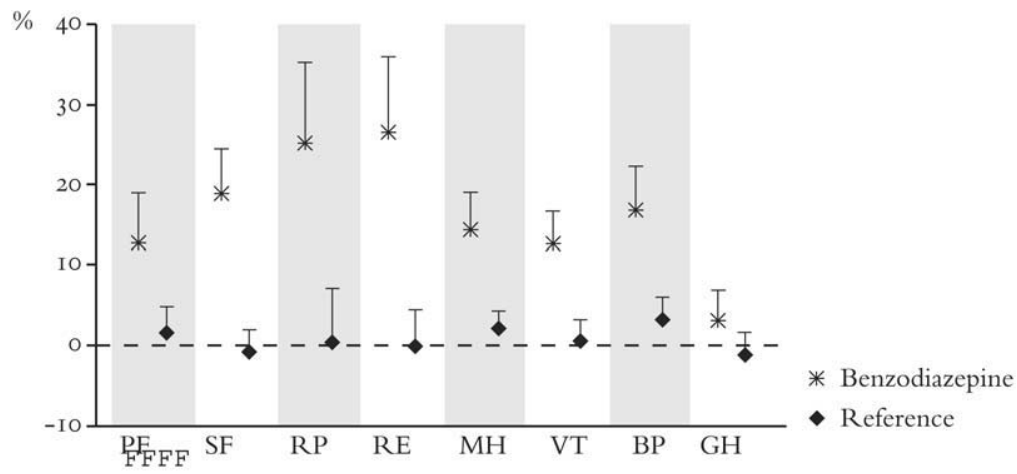

Figure 1 Change (absolute percentage) for all domains of health-related quality of life in initial benzodiazepine users (BZD) and reference subjects (REF) after a six-month follow-up. PF = physical functioning; SF = social functioning; $R P=$ role limitation (due to physical problems); $R E=$ role limitation (due to emotional problems); $M H=$ mental health; $V T=$ vitality; $B P=$ pain; $G H=$ general health perception. 
benzodiazepines was responsible for the increase in HRQOL. We defined both physical and mental functioning on the basis of two component summaries derived from the RAND-36. This questionnaire has been demonstrated to be a good tool to observe changes in HRQOL over time. Furthermore, it provides insight in the general health status over a broad spectrum of subscales ${ }^{26-28}$. Within the group of initial benzodiazepine users, an improvement in health status with benzodiazepine usage characteristics was observed, such as the benzodiazepine initially prescribed, period of use and dosage. A second limitation of the current study is the absence of data on the indication for the initial benzodiazepine. Therefore, the design of the study could not control for the absence of confounding by indication. It is well known, that benzodiazepines are generally prescribed for a limited range of psychogenic disorders such as anxiety, panic disorders and in insomnia and muscle spasm. The higher CDS of benzodiazepine users before inclusion is an indication of the initial presence of chronic somatic disease. This finding, together with the higher health service utilisation in the period of 12 months before inclusion, illustrates a group of initial benzodiazepine users with a higher morbidity than the general population and with morbidity that is already present a considerable time before the start of the use of the benzodiazepine. Seen the results of the study, we suggest that the role of benzodiazepines in the improvement of HRQOL requires further investigation in a more sophisticated study design, e.g., controlled with a reference group with the same indication.

Within the group of initial benzodiazepine users, we analysed the association between improvement in health status and benzodiazepine-usage characteristics. An improvement in physical functioning was associated with male gender and initial diazepam use. The latter association raises the question whether diazepam was prescribed for the treatment of a physical disorder or not. If so, benzodiazepines, mainly diazepam, can be prescribed in the treatment of muscular spasm. However, the efficacy of diazepam in the condition muscular spasm is under discussion ${ }^{34}$. There is also the possibility of off-label prescribing of the benzodiazepine. An increase in mental functioning was related to younger age, a period of use between 16 to 60 days, and a low dosage of the benzodiazepine. These findings indicate an improved therapeutic result

Table 2 Difference in health-related quality of life between initial benzodiazepine users (BZD) and reference subjects at baseline and at six-month follow-up*

\begin{tabular}{|c|c|c|c|c|c|c|c|c|}
\hline & \multicolumn{4}{|c|}{ Baseline } & \multicolumn{4}{|c|}{ Six-month follow-up } \\
\hline & \multicolumn{2}{|l|}{$B Z D$} & \multicolumn{2}{|c|}{ Reference } & \multicolumn{2}{|l|}{ Benzo } & \multicolumn{2}{|c|}{ Reference } \\
\hline & Mean & Median & Mean & Median & Mean & Median & Mean & Median \\
\hline Physical functioning & 70.9 & 80.0 & 85.3 & 95.0 & 11.9 & 5.0 & 1.0 & 0.0 \\
\hline Social functioning & 65.2 & 62.5 & 90.2 & 100.0 & 18.2 & 12.5 & -0.7 & 0.0 \\
\hline Role limitation (physical problems) & 50.9 & 58.3 & 87.0 & 100.0 & 24.1 & 0.0 & 0.5 & 0.0 \\
\hline Role limitation (emotional problems) & 59.4 & 66.7 & 94.1 & 100.0 & 26.6 & 0.0 & -0.3 & 0.0 \\
\hline Mental health & 60.9 & 60.0 & 81.9 & 84.0 & 13.5 & 8.0 & 2.3 & 4.0 \\
\hline Vitality & 52.1 & 50.0 & 70.0 & 75.0 & 11.5 & 10.0 & 0.7 & 0.0 \\
\hline Pain & 65.7 & 67.3 & 86.3 & 100.0 & 15.9 & 10.2 & 3.2 & 0.0 \\
\hline General health perception & 63.2 & 65.0 & 74.7 & 80.0 & 3.1 & 5.0 & -0.7 & 0.0 \\
\hline
\end{tabular}

*All differences between reference subjects and initial benzodiazepine users were statistically significant $(P<0.05$; Wilcoxon's paired signed rank test).

Table 3 Benzodiazepine usage characteristics

\begin{tabular}{|c|c|c|c|}
\hline & & $n$ & $\%$ \\
\hline \multirow[t]{4}{*}{ Initial benzodiazepine } & Diazepam & 41 & 38.7 \\
\hline & Oxazepam & 26 & 24.5 \\
\hline & Temazepam & 16 & 15.1 \\
\hline & Other & 23 & 21.7 \\
\hline \multirow[t]{3}{*}{ Period of use } & $<16$ days & 71 & 67.0 \\
\hline & $16-60$ days & 24 & 22.6 \\
\hline & $>60$ days & 11 & 10.4 \\
\hline Episodes of use & 1 & 83 & 78.3 \\
\hline \multirow[t]{4}{*}{ DDD class } & $>1$ & 13 & 21.7 \\
\hline & $<0.75$ & 58 & 54.7 \\
\hline & $0.75-1.25$ & 38 & 35.8 \\
\hline & $>1.25$ & 10 & 9.4 \\
\hline Switching & & 5 & 4.7 \\
\hline
\end{tabular}


Table 4 Logistic regression modelling of change in two component scores of health-related quality of life over time

\begin{tabular}{|c|c|c|c|c|c|}
\hline \multirow[t]{2}{*}{ Change } & & \multicolumn{2}{|l|}{ PCS* } & \multicolumn{2}{|c|}{$M C S^{\#}$} \\
\hline & & $O R$ & $95 \% \mathrm{Cl}$ & OR & $95 \% \mathrm{Cl}$ \\
\hline \multirow[t]{2}{*}{ Gender } & Male & 1.00 & & 1.00 & \\
\hline & Female & 0.24 & $(0.07-0.83)$ & 0.80 & $(0.26-2.51)$ \\
\hline \multirow[t]{3}{*}{ Age } & $<40$ & 1.00 & & 1.00 & \\
\hline & $40-60$ & 0.97 & $(0.29-3.27)$ & 0.29 & $(0.09-0.93)$ \\
\hline & $>60$ & 0.30 & $(0.03-2.76)$ & 0.18 & $(0.03-1.13)$ \\
\hline \multirow[t]{4}{*}{ Initial BZD } & Diazepam & 1.00 & & 1.00 & \\
\hline & Oxazepam & 0.13 & $(0.02-0.75)$ & 2.54 & $(0.60-10.84)$ \\
\hline & Temazepam & 0.10 & $(0.01-0.76)$ & 3.91 & $(0.79-19.38)$ \\
\hline & Other & 0.07 & $(0.01-0.38)$ & 7.58 & $(1.67-34.47)$ \\
\hline \multirow[t]{3}{*}{ Period of use } & $<16$ & 1.00 & & 1.00 & \\
\hline & $16-60$ & 2.55 & $(0.29-22.46)$ & 6.96 & $(1.03-47.16)$ \\
\hline & $>60$ & 0.24 & $(0.01-5.81)$ & 1.88 & $(0.27-12.94)$ \\
\hline \multirow[t]{2}{*}{ Episodes of use } & 1 & 1.00 & & 1.00 & \\
\hline & $>1$ & 0.23 & $(0.02-2.84)$ & 0.30 & $(0.06-1.52)$ \\
\hline \multirow[t]{3}{*}{ DDD class } & $<0.75$ & 1.00 & & 1.00 & \\
\hline & $0.75-1.25$ & 3.68 & $(0.85-15.90)$ & 0.20 & $(0.05-0.83)$ \\
\hline & $>1.25$ & 0.75 & $(0.11-5.31)$ & 0.07 & $(0.01-0.97)$ \\
\hline
\end{tabular}

*PCS indicates physical component score.

"MCS indicates mental component score.

of benzodiazepines with respect to a younger age, limited duration and a low dosage. These findings support the recommendations for limited use of these drugs.

Another study in the same study population showed that the psychological variable 'perceived benefits of benzodiazepines' at the start of use turned out to be a determinant of increase in the intention to use benzodiazepines after the first six months of use ${ }^{35}$. These perceived benefits of benzodiazepines at the start together with another perceived benefit, namely the improvement of the HRQOL of the user during the initial six months, might form a positive attitude of the user towards prolonged use. It is the responsibility of physician and pharmacist to give actively information in that period by focussing attention on the risks of prolonged benzodiazepine use such as dependence and difficulty to discontinue.

\section{Conclusions}

In conclusion, this study has shown an association between first-time benzodiazepine use and an improved health status during a longer period of follow-up. Observed associations with specific benzodiazepine usage characteristics might provide an argument in favour of placing restrictions on benzodiazepine prescribing in terms of limited duration and a low dosage.

\section{References}

1 Hollister LE. The pre-benzodiazepine era. Psychoactive Drugs 1983; 15: 1-2, 9-13.

2 Hollister L, Molzenbecker F, Degan R. Withdrawal reactions from chlordiazepoxide (Librium). Psychopharmacologia 1961; 2: 63-8.

3 Petursson $\mathrm{H}$, Lader $\mathrm{MH}$. Benzodiazepine dependence. $\mathrm{Br}$ J Addict 1981; 76: 133-45.
4 Lader MH. Dependence on benzodiazepines. J Clin Psychiatry 1983; 44: 121-7.

5 Owen RT, Tyrer P. Benzodiazepine dependence: a review of evidence. Drugs 1983; 25: 385-98.

6 Mellinger GD, Balter MB, Uhlenhuth EH. Anti-anxiety agents: duration of use and characteristics of users in the U.S.A. Curr Med Res Opin 1984; 8 (Suppl): 4.

7 Olfson M, Pincus HA. Use of benzodiazepines in the community. Arch Intern Med 1994; 154: 1235-40.

8 Dunbar GC, Perera MH, Jenner FA. Patterns of benzodiazepine use in Great Britain as measured by a General Population Survey. $\mathrm{Br} J$ Psychiatry 1989; 155: 836-41.

9 Tyrer P, Owen R. Anxiety in primary care: is short term drug treatment appropriate? J Psychiatr Res 1984; 18: 73-8.

10 Lader MH, Petursson H. Rational use of anxiolytic/sedative drugs. Drugs 1983; 25: 514-28.

11 Committee on the review of medicines. Systematic review of the benzodiazepines. BMJ 1980; 141: 917-21.

12 Greenblatt DJ, Shader RI. Benzodiazepines in clinical practice. New York: Raven Press, 1974.

13 Rickles K, Downing RW. Drug and placebo treated neurotic outpatients. Arch Gen Psychiatry 1976; 16: 369-72.

14 Dasberg H, Van Praag HM. The therapeutic effect of short term oral diazepam treatment on acute clinical anxiety in a crisis centre. Acta Psychiatr Scand 1974; 50: 326-40.

15 Shapiro AK, Sruening EL, Shapiro E, Milcarek BI. Diazepam: how much better than placebo? I Psychiatric Res 1984; 18: 51-73.

16 Catalan J, Gath D. Benzodiazepines in general practice: time for a decision. BMJ 1985; 290: 1374-6.

17 Catalan I, Gath DH, Bond A, Edmonds G, Martin P, Ennis ]. General practice patients on long term psychotropic drugs. $\mathrm{Br} J$ Psychiatry 1988; 152: 399.

18 Mellinger GD, Balter MB, Uhlenhuth EH. Prevalence and correlates of the long-term use of anxiolytics. JAMA 1984; 251: $375-9$.

19 Simpson RJ, Power KG, Wallace LA, Butcher MH, Swanson V, Simpson EC. Controlled comparison of the characteristics of long-term benzodiazepine users in general practice. $\mathrm{Br}$ J Gen Pract 1990; 40: 22-6.

20 Rodrigo EK, King MB, Williams P. Health of long term benzodiazepine users. BMJ 1988; 296: 603-6.

21 Mant A, Mattick RP, De Burgh S, Donnelly N, Hall W. Benzodiazepine prescribing in general practice: dispelling some myths. Fam Pract 1995; 12: 37-43.

22 Romach M, Busto U, Somer G, Kaplan HL, Sellers E. Clinical aspects of chronic use of alprazolam and lorazepam. Am J Psychiatry $1995 ; 152: 1161-7$. 
23 Van Hulten R, Characteristics of current benzodiazepine users as indicators of differences in physical and mental health. Pharm World Sci 2000; 22: 96-101.

24 Marino S. III-health and social predictors of psychotropic drug prescription in general practice. Int J Soc Psychiatry 1993; 39: 167-76.

25 Douglas Ried L, Johnson RE, Gettman DA. Benzodiazepine exposure and functional status in older people. J Am Geriatr Soc 1998; 46: 71-6.

26 Ashton $\mathrm{H}$. Guidelines for the rational use of benzodiazepines. What and what to use. Drugs 1994; 48: 24-40.

27 Van der Zee KI, Sanderman R. Het meten van de algemene gezondheidstoestand met de RAND-36. Een handleiding. [Measuring general health status with the RAND-36. Users manual.] Groningen, The Netherlands: Northern Center of Health Care Research, 1993 [in Dutch].

28 Ware JE, Sherbourne CD. The MOS 36-Item Short-Form Health Survey (SF-36), I: Conceptual framework and item selection. Med Care 1992; 30: 473-83.

29 Hays RD, Sherbourne CD, Mazel RM. The RAND 36-Item Health Survey 1.0. Health Econ 1993; 2: 217-27.
30 Ware JE, Koskinski M, Keller SD. SF-36 physical and mental summary scales: a user's manual. Boston, Massachusetts: The Health Institute, 1994.

31 Ware JE, Kosinski M, Bayliss MS, McHorney CA, Rogers WH, Raczek A. Comparison of Methods for the Scoring and Statistical Analysis of SF-36 health profile and summary measures: Summary of results from the medical putcome study. Med Care 1995; 33: AS264-79.

32 Morrin L, Black S, Reid R. Impact of duration in a cardiac rehabilitation program on coronary risk profile and health-related quality of life outcomes. J Cardiopulm Rehab 2000; 20: 115-21.

33 Von Korf M, Wagner EH, Saunders K. A chronic disease score from automated pharmacy data. J Clin Epidemiol 1992; 45: 197-203.

34 Nazareth ID, King MD. Prescribing of benzodiazepines by casualty officers. J R Soc Med 1989; 82: 276-7.

35 Van Hulten R, Bakker AB, Lodder AC, Teeuw KB, Bakker A Leufkens HG Determinants of change in the intention to use benzodiazepines. Pharm World Sci 2001; 23: 70-5. 